\title{
La historia de los conceptos y las prácticas del lenguaje en la construcción de competencias en el campo de la educación superior
}

\author{
The History of Concepts and Language Practices \\ in Building Skills in the Field of Higher Education
}

Miguel Ángel Maldonado García*

Recibido: 9 de octubre de 2012

Aceptado: 6 de noviembre de 2012

\section{Resumen}

Este artículo presenta los resultados de investigación y los fundamentos básicos de la historia de los conceptos, empleada como método de trabajo de la tesis doctoral del autor del texto. La historia conceptual es un método con enfoque hermenéutico que permite indagar cómo una palabra se convierte en un concepto en los diferentes estratos del tiempo. La investigación permitió comprender, describir y analizar cómo los enunciados y los discursos construidos a partir del concepto de competencia han hecho posible la movilización de políticas de cubrimiento nacional e internacional, tanto en el mundo educativo como en el mundo empresarial.

Palabras clave: competencia, lenguaje, historia de los conceptos, revolución, Robinson.

\section{Abstract}

This research article presents the results of the basics aspects of the history of concepts which was used as a method of work of the doctoral thesis entitled The Conceptual Offensives about Skills in the Field of High Education and the Work in Colombia. Period, 1957-2004" (Maldonado, 2012). The conceptual history is a method with a hermeneutic approach that allows to investigate how a word becomes a concept in the different strata of the time. The story concept is a hermeneutic method that allows to investigate how a word be comes a concept in different strata of time. The investigation to understand, describe and analyze how the statements and speeches of the concept constructed from competition have made possible the political mobilization of national and international coverage through discursive tensions waving a metaphor for working subject in both the educational and in the business world.

Key words: competence, language, history of concepts, revolution, Robinson.

* Doctor en Educación, Convenio Interinstitucional Universidad Pedagógica Nacional, Universidad Distrital y Universidad del Valle. Profesor asistente de la Maestría en Pedagogía de la Lengua Materna, Universidad Distrital Francisco José de Caldas. Correo electrónico: avancemosenpedagogia@gmail.com 


\section{Introducción}

Con el fin de comprender mejor las mutaciones del concepto competencia, este artículo se divide en dos partes. En primera instancia aborda la historia de los conceptos y luego muestra los resultados de la investigación en ciernes, la cual da cuenta de cómo se pone en práctica la propuesta de Koselleck (1993, 2001, 2004). La primera parte muestra cómo la historia de los conceptos construye categorías útiles para la reconstrucción de conceptos borrosos y la segunda hace una semblanza de este proceso en el concepto de competencia. Si bien la primera parte es un tanto densa, consideramos pertinente que el lector comprenda su valía.

El concepto de competencia nació en el siglo XVIII. En un proceso de larga duración, ha venido cambiando su sustancia, y cabalgando lenta y silenciosamente en textos canónicos, pero de pronto este cambio sufrió una aceleración a finales del siglo XX. Desemboca en Colombia y se encuentra con enunciados de revolución, competitividad, evaluación, acreditación y competencias, en el contexto de la educación básica y superior como fábrica del conocimiento. Aunque el periodo trazado fue entre 1957 y 2004, en el desarrollo de la investigación se identificó que este estrato temporal era solo la punta de un iceberg, que tenía una superficie muy ancha y profunda cubierta con el líquido del tiempo.

En un recorrido de largo aliento por la dispersión escritural de Europa y América, producida luego de publicadas La riqueza de las naciones (1776) de Adam Smith y Emilio o la educación de Rousseau (1762), se estudió el asunto en Colombia y se observó cómo diversos grupos en contienda resemantizaron esta palabra en distintos lugares y tiempos, hasta convertirla en un concepto de uso obligado para la educación y el trabajo.
Este ejercicio investigativo apela a la historia de los conceptos de Koselleck $(2001,2004)$, pero no desdeña otras categorías de análisis discursivo ${ }^{1}$. La irrupción de palabras, conceptos y textos relacionados con competencias se hace cada día más notoria en el campo educativo y laboral, en lo público y en lo privado, tanto en Europa como en Latinoamérica, hasta alcanzar una postura histórica y una enorme producción discursiva, y, por esta razón, asumimos esta opción epistémica.

Valga acotar que el propósito de esta investigación no es denunciar la desconfiguración de una categoría científica proveniente de la lingüística u otra disciplina ni defender un episteme particular; tampoco pretende velar por la pureza del término competencia. Las transformaciones observadas no son producto de un proceso de contaminación o degradación lingüística de dicha palabra, son, más bien, el resultado de juegos de poder en los que los sujetos cambian las palabras y las palabras cambian a los sujetos.

Algunos discursos locales tienen sedimentos en el periodo republicano y en la primera mitad del siglo XX. En su momento se tomaron los campos de poder de la intelectualidad de turno y dejaron disputas irresueltas que cambiaron de forma y de propósitos en otras capas temporales. Tensiones como las del juicio a los títulos nobiliarios de la Colonia vs. la profesionalización, la limpieza de sangre para acceder a la educación superior, o la rivalidad de mediados del siglo XIX entre una educación útil y una educación inútil dejaron sedimentos y enunciados que tomaron nuevas formas y rumbos. Estas tensiones se remozaron sin cesar: tomaron la forma de alfabetización e higienización; construyeron centros para el

1 Hacemos referencia a estas categorías de análisis desde la perspectiva desarrollada especialmente por Michel Foucault (1979, 2005); Reinhard Koselleck (1993, 1994 2003), Quentin Skinner (2007), Elías Palti (2006) y Michel de Certeau. 
trabajo o para la formación de obreros; o, de modo reciente, formaron para el desarrollo de competencias laborales y otras maneras, como la universidad productiva o fábrica del conocimiento. Cada nuevo proyecto tiene su propia crisis; así, se han generado prácticas y discursos pedagógicos que solapan diversas crisis y que suelen aparecer precedidas del concepto revolución. Un día fueron revoluciones con fines de alfabetización o para el saneamiento de la población, otro día fueron revoluciones asociadas con la formación para el trabajo o, en los últimos tiempos, revoluciones educativas que auspician las competencias laborales, matemáticas o lingüísticas.

Si se aceptan estos planteamientos, es posible comprender la forma como se fue construyendo un archivo con revistas, periódicos, libros, folletos, leyes, expedientes jurídicos, decretos, novelas, registros de Internet y otros textos poco convencionales, o al menos poco reconocidos en el escenario educativo, como documentos históricos generadores de la producción discursiva de la modernidad. La remoción de distintas capas temporales discursivas descubrió enunciados tales como: hombres heroicos, trabajador emprendedor, mujer laboriosa y hombre heroico, niño obediente, Revolución en Marcha (propiciada por el presidente Alfonso López Pumarejo), Revolución de la Esperanza (propiciada por la Acción Cultural Popular ACPO-Sutatenza), Revolución Pacífica (propiciada por el Servicio Nacional de Aprendizaje [SENA]) y Revolución Educativa (propiciada por los presidentes Andrés Pastrana y Álvaro Uribe) enunciados que crearon las condiciones de posibilidad asociadas a la construcción del concepto de competencia.

\section{Metodología}

El soporte teórico metodológico de esta investigación reside en la perspectiva de Koselleck y su historia de los conceptos o historia conceptual, a partir de la cual se hace la búsqueda, el ordenamiento documental, la datación temática, el manejo de fuentes y la construcción del texto. Adelantamos esta labor sin menoscabo de otros aportes, como el de la escuela de Cambridge, algunas prácticas foucaultianas relacionadas con la arqueología, y uno que otro de Michel de Certeau.

En vista de que esta investigación se soporta en la historia de los conceptos, fue preciso recurrir a la filología histórica en dos sentidos: el estudio semasiológico -o búsqueda del significado de las palabras- y el estudio onomasiológico - o búsqueda de la variedad de significaciones de un concepto-. Se construyó un campo semántico, entendido como el escenario en el cual se tensionan los discursos y posturas en torno a las competencias, basado en un archivo enorme conformado por cánones literarios, investigaciones y textos institucionales que se encontraron en el SENA. Dicho campo fundó cuatro categorías antitéticas y trascendentales, una menos de las propuestas por Kosselleck.

\section{Sustratos temporales y fuentes consultadas}

Se armó un archivo, con el fin de mirar los textos como instancias de poder, en cuatro grandes bloques. El primer estrato de tiempo parte de cuatro textos literarios y uno económico que facilitaron el desarrollo de tres acciones: la aproximación al objeto de estudio, el armazón del archivo en medio de una enorme dispersión documental y la estratificación temporal. Gracias a que la investigación conceptual de esta índole considera la literatura como un objeto de estudio, tomamos cuatro textos que permitieron el despegue y el recorrido por otros lugares y tiempos: La tempestad (1612), de William Shakespeare; Robinson Crusoe (1719), de Daniel Defoe; Emilio (1762), de Jean Jacques Rousseau, y La riqueza de las naciones (1776), de Adam Smith. ${ }^{2}$ El segundo estrato

2 Este texto, aunque de carácter económico, fue leído por sus contemporáneos desde la misma perspectiva estética de los textos literarios señalados, y desde las orillas de la Revolución Industrial inglesa y de la Revolución francesa. 
de tiempo se establece a partir de las ediciones pedagógicas de Simón Rodríguez ${ }^{3}$ (1794), dado que sus obras fueron un puente entre Europa y Latinoamérica: tanto Rousseau como Rodríguez son maestros paradigmáticos que formaron héroes románticos en sus respectivos discípulos y sembraron sus discursos en los siguientes textos: El triunfo de Calibán (1897), de Rubén Darío. Ariel (1900), de José Enrique Rodó, y De Robinson a Odiseo. Pedagogías estructurativas (1935), de José Vasconcelos. Estos autores-actores crean su propio sujeto heroico y letrado, y una acepción criolla de racismo, y estimulan una versión moderna en Latinoamérica del trabajador obediente en circunstancias que agitan enunciados como revolución, civilización, raza y barbarie. El tercer periodo comprende dos grupos: por una parte, textos literarios asociados a la emergencia de la ACPO (1947) y el SENA ${ }^{4}$ (1957); y por otra, textos o resultados de investigaciones de personas, grupos de investigación de universidades públicas y otras instituciones comprometidas con el concepto de competencia, ora como como defensores ora como detractores, no solo en Colombia, sino también en Inglaterra, España, México y Estados Unidos. En el ámbito institucional y para la segunda mitad del siglo XX y comienzos del XXI, se observaron las proclamas del Centro Interamericano de Investigación y Documentación sobre Formación Profesional (Cinterfor), la Organización de las Naciones Unidas para la Educación, la Ciencia y la Cultura (Unesco), la Organización Internacional del y Trabajo (OIT), el proyecto de rediseño curricular Alfa Tuning, el Proyecto $6 \mathrm{x}$ 4 , entre otros, además de normas y decretos que aus-

3 Simón Rodríguez publicó en Caracas en 1794 el texto Estado actual de la escuela y nuevo establecimiento de ella.

4 Destacamos que se armó un archivo particular con documentos del Servicio Nacional de Aprendizaje (SENA) en los que se enuncia el concepto con insistencia, y que sirve de referente para muchas universidades y empresas. pician el concepto en ciernes, como el Ministerio de Educación Nacional y sus agencias locales. Nuestro propósito era observar cómo sus posturas se convierten en escenarios de poder desde donde cada quien defiende lo suyo; pero en este juego se hacen visibles $y$, a pesar de que se conviertan en detractores del concepto, terminan por auspiciar y empoderan el concepto en diversos lugares y estratos de tiempo.

\section{Fundamentos de la historia de los conceptos}

La historia conceptual o historia de los conceptos tomó cuerpo en las escuelas de Bielefeld (Alemania), y de Cambridge, (Inglaterra), y se convirtió en un instrumento propicio para abordar las tensiones o fricciones políticas, ideológicas, culturales y semiológicas generadas entre grupos que asumen un concepto en sus prácticas discursivas para librar sus batallas por el capital académico.

No obstante su capacidad y logro, las investigaciones sobre historia de los conceptos - en cuanto método histórico para indagar los juegos del lenguaje en un contexto político social específico- no son muy visibles en el escenario colombiano, donde apenas se presume su existencia o se conoce un par de obras de autores extranjeros. La tradición más fuerte se encuentra en Europa. Emerge en el periodo de posguerra con el giro lingüístico, ${ }^{5}$ del que se abren dos caminos por donde vienen transitando los investigadores: el primero nos conduce a la escuela alemana fundada por Reinhart Koselleck y el segundo nos sitúa en la escuela de Cambridge, en cabeza de John G. A. Pocock y Quentin Skinner, y a la cual haremos pocas referencias. El camino a la escuela de Koselleck, o de la Universidad de Bielefeld, pasa por el existencialismo

5 Utilizamos este concepto según los planteamientos de Gustav Bergmann, difundidos por el norteamericano Richard Rorty, quien en El giro lingüístico (1967/1990) anuncia que la filosofía y la lingüística han propiciado un cambio fundamental en la comprensión del hombre y la sociedad. Véase, además, Suárez (2005) y Rojas (2006). 
de Martin Heidegger (2005), la hermenéutica de Hans-Georg Gadamer (2002), la política de Carl Schmitt (Orestes, 2001), el humanismo de Hannah Arendt (2005), la lingüística de Ferdinand de Saussure (2005) y la historia crítica de Wilhelm Dilthey (1960), hasta desembocar en la histórica, empleada por Kosselleck. El camino a la escuela analítica inglesa de Cambridge, entre tanto, pasa por la historia de las ideas políticas que deviene en los actos de habla trazados desde Ludwig Wittgenstein (2003) y que se actualizan con John L. Austin (1991), John Searle (2001) y Thomas Kuhn (2006). En su andar, la escuela de Cambridge se acerca a la arqueología de Michel Foucault $(1979,2005)$ y a la producción discursiva de Jacques Derrida (1971). Al comenzar el siglo XXI estas dos escuelas se extienden a Suecia, Italia y España y luego, en la versión hispana, se embarcan hacia Latinoamérica como historia intelectual o historia del pensamiento político, especialmente gracias al argentino Elías Palti $(2001,2003,2007) .{ }^{6}$

Koselleck, con su historia de los conceptos o historia conceptual, ofrece a los investigadores del lenguaje instrumentos de trabajo para la búsqueda, el ordenamiento documental, la datación temática, el manejo de fuentes y la reconstrucción de textos borrosos por la niebla de la historia. Ir tras las huellas de Koselleck, hasta llegar a la síntesis de la historia de los conceptos, nos sitúa en los años sesenta y setenta, y nos permite delinear un dispositivo de investigación. Por esta razón haremos un rápido recorrido por los espacios y momentos clave que muestran cómo y cuándo este investigador alemán construyó su

6 José Elías Palti es un prolífico investigador argentino (profesor de la Universidad de Quilmes, del Colegio de México y del Consejo Nacional de Investigaciones Científicas y Técnicas [Conicet]) que ha tratado de zafarse de las escuelas canónicas señaladas y ha explorado en la genealogía foucaultiana. En sus últimas producciones se muestra más cerca de la escuela de Cambridge y sitúa sus investigaciones como historia de las ideas intelectuales o políticas. metodología. El recorrido señala un paralelo entre los aspectos claves desarrollados por Quentin Skinner y la historia de las ideas intelectuales, hasta llegar al experimento de fusión de estas metodologías.

\section{La escuela de Bielefeld}

Para Koselleck, un análisis conceptual guarda relación con la búsqueda de los acontecimientos políticos o sociales en los que se observa una especie de oleaje en cuyo movimiento desaparecen unos conceptos que les dan vida a otros. Desde este punto de vista, se parte del presupuesto de que el concepto ya está creado en tanto existen diversos discursos o textos lingüísticos y extralingüísticos, y experiencias históricas o prácticas sociales que corroboran su existencia, pero que circulan de modo azaroso en distintos momentos y lugares. Por esta razón es preciso hacer estratificaciones sincrónicas y diacrónicas de los acontecimientos que permitan captarlos en planos fotográficos y cinematográficos, respectivamente.

Luego del interés suscitado por su tesis doctoral, ${ }^{7}$ los historiadores alemanes Otto Brunner (1898-1962) y Werner Conze (1910-1986), sus dos maestros, comprometen a Koselleck en la enorme empresa de armar un diccionario con los conceptos políticos germánicos de la modernidad, bajo el título de Geschichtliche Grundbegriffe. Esta obra magistral - que dado su alcance y envergadura, aunque con pretensiones distintas, no es menor que la Enciclopedia del Siglo de las Luces- explora dos aspectos fundamentales, a saber: la importancia que otorga el autor al análisis de los conceptos en cuanto registros de la realidad y la convicción de que dichos conceptos transforman la realidad que los hizo posibles. Ambos aspectos confluyen en el término histórica,

7 Crítica y crisis. Estudio sobre la patogénesis del mundo burgués (1959), tesis doctoral dirigida por Carl Schmitt que fuera traducida al castellano por Rafael de la Vega y Jorge Pérez de Tudela, y publicada en 2007 por la editorial Trotta. 
basado en el planteamiento kantiano - a partir de la experiencia de la aceleración y temporalización de la historia que caracteriza a la modernidad como épo$\mathrm{ca}-$, en cuya singularidad asume el giro lingüístico para darle cabida al lenguaje como la primera interpretación del mundo.

Losestratosdel Tiempo(2001)eHistoria/historia(2004) sintetizan la perspectiva metodológica expuesta en Futuro pasado (1993), que le permitirá avanzar con la escritura de tres diccionarios ${ }^{8}$ monumentales. Por otra parte, fue revelador el diálogo que Koselleck sostuviera con Gadamer (Koselleck y Gadamer, 1997) pues evidencia, tanto su influjo inicial como su desprendimiento de la hermenéutica existencial de quien fuera su maestro, a quien le dirá que la historia de los conceptos no es un apéndice de la historia ni tampoco de la hermenéutica. Se puede decir que con Historia / historia se escribe el prólogo de los diccionarios que inició junto con Brunner y Conze, para declarar que su búsqueda histórica es ante todo una faena de lenguaje. De acuerdo con Palti (2001), en los tres diccionarios subyace una teoría de la historia o Historik como una "doctrina de las condiciones de posibilidad de las historias" (p. 9). Según Koselleck, la historia es un neologismo de la modernidad germana, que se construyó en la dinámica política y social comprendida en el campo de experiencia y el horizonte de expectativa a partir de la Revolución francesa. Estas dos categorías son el basamento de su proyecto histórico que, a más de comprometer a los historiadores en los futuribles, les asigna responsabi-

8 Geschichtliche Grundbegriff. Historisches Lexicon zur Politisch - zocialen Sparchein Deutschland (Conceptos básicos de historia. Un diccionario sobre principios del lenguaje politico social en Alemania, Stuttgart, 1972-1997), Historisches Worterbuch der Philosophie (Diccionario de filosofía de principios históricos, Basilea, 1971-) y Handbuch politisch-sozialer Grundbegriffe in Frankreich, 1680-1820 (Manual de conceptos político-sociales en Francia, 1680-1820) (Munich, 1985). En la introducción de Koselleck (2001). lidad sociopolítica: recuerdo y esperanza son la sustancia de lo que ya existe y de lo que está por existir.

En Futuro pasado sustenta y demuestra sus pares dicotómicos con evidencias históricas que van desde las confrontaciones entre helenos y bárbaros, cristianos y paganos, hasta el holocausto nazi. De acuerdo con Koselleck, estos pares representan la humanidad, física, espacial, espiritual, teológica o temporalmente, y dejan evidencias de que estas categorías están en todas las historias posibles. Estas son básicas para la investigación de conceptos borrosos, y a cada una corresponde una breve sustentación del propio Koselleck (Koselleck y Gadamer 1997). ${ }^{9}$

Koselleck considera que el concepto de historia surge después de dos dilatados procesos que confluyen en un campo de experiencia:

9 1) Deber morir y poder matar: "Desde las hordas recolectoras y cazadoras, hasta las superpotencias bien equipadas de armas atómicas, la lucha por la supervivencia está siempre bajo la amenaza de muerte a los otros o más aún proferida por los otros. Esta amenaza puede, como es sabido, limitar el uso excesivo de la fuerza" (Koselleck y Gadamer, 1997, p. 74). 2) Amigo-enemigo: "En el reconocimiento del otro como enemigo y no como encarnación del mal que se debe erradicar ya se alberga una esperanza de paz" (p. 77). 3) Interior-exterior, secreto-público: categoría heideggeriana del ser en el mundo. Esa oposición estructura las condiciones de todas las historias posibles. "No hay ninguna historia de amor que no se cree sus propias relaciones internas y externas, por cuya tensión no se deje al mismo tiempo transportar" (p. 77) 4) Padres-hijos: toma la categoría generatividad o natividad de Hannah Arendt. "La sucesión inevitable de generaciones, en su reengendradora superposición fática y temporal, lleva siempre a nuevas exclusiones, a determinaciones diacrónicas de lo interno externo, al antes o al después respecto a las unidades de experiencia específicas de cada generación. Sin estas exclusiones ninguna historia es pensable" (p. 82). 5) Señor-esclavo, abajo-arriba, fuerte-débil: "Toda revolución que ha alterado las relaciones de fuerza de modo violento acaba estableciendo nuevas relaciones de fuerza. La legitimación será tal vez nueva, otras serán las relaciones jurídicas, quizás incluso mejore pero nunca se ha cambiado en nada la relación arriba-abajo" (p. 84). 
El primero consiste en la formación del colectivo singular que aglutina en un concepto común la suma de las historias individuales. El segundo en la fusión de "historia" como conexión de acontecimientos y de "Historia" en el sentido de indagación histórica, ciencia o relato de la historia. (2004, p. 27)

Las historias singulares se dan cita para construir la historia (Koselleck, 2004, p. 27). Según Koselleck, este concepto avanza desde una reflexión estética, juegos e intercambios, inclusiones, desapariciones, modificaciones y traslapamientos de palabras que luego se convierten en un concepto. Se produce una fusión de historias, desmoralización y un proceso complejo hasta lograr un matiz racional y cumplir funciones sociales y políticas en un escenario situado temporalmente.

El primer proceso o surgimiento del colectivo singular está regulado por varios aspectos: el encuentro entre historias particulares o acontecimientos, las pretensiones de verdad, la fusión de estas dos con una historia general y, especialmente, por su connotación política.

En el segundo proceso, se produce una reflexión estética. Lo racional se combina con lo poético para aumentar las posibilidades. Koselleck muestra su catadura aristotélica y señala que la historia solo narraría lo que ha pasado, mientras que la poesía narraría lo que podría pasar. Así, la estética poética se desenvuelve en el plano de lo posible, filosófico y universal, ampliando el espacio de expectativa: a diferencia del historiador el poeta puede juntar eventos "injuntables". La moralización surge cuando se procesa la historia y le apuesta a una verdad histórica y, aunque minimiza su tono pragmático para ingresar en el plano estético literario, gana en capacidad de persuasión y credibilidad: "Se crea así una 'historia veraz' y funda unidades de sentido" (2004, pp. 51-52). Koselleck encontró que el tono trascendentalista, didáctico y objetivista, así como el uso del pronóstico pragmá- tico y las pretensiones de escribir lecciones para la vida, dejarán de ser lo esencial de la historia.

Los dos procesos señalados, concluye Koselleck, lograrán entonces la unidad estética de sentido de la exposición histórica (historisch), la moral que se exigía o se pretendía obtener de la historia y, finalmente, la construcción conforme a razón de una historia posible: todos estos factores se ensamblaron para producir una filosofía de la historia que, en definitiva, ponía y reconocía la "historia misma" como racional (2004, pp. 70-71).

Así, la histórica forjó su método, ganó espacio y se hizo visible en el escenario de las ciencias (2004, p. 78).

\section{Estratificación del tiempo}

Koselleck sintetiza el proceso fundado sobre los principios investigativos de la historia en Los estratos del tiempo: estudios sobre la historia (2001), libro en el que expone una versión de las distintas categorías de tiempo en relación con el método, la experiencia, las velocidades y la contingencia, más que como categoría metafísica. Koselleck toma los instrumentos de la geología para dibujar una metáfora denominada estrato a partir de la cual describe las representaciones que la experiencia humana hace del tiempo. Así lo señala: "Cuando hablemos en adelante de estratos del tiempo deberá pensarse también en los hallazgos de la experiencia, descifrados analíticamente en tres estratos" (2001, p. 30). Se refiere a observar los relatos en unicidad, recurrencia y trascendencia. ${ }^{10}$

10 Unicidad: el primer conjunto de experiencia suele presentarse de modo irreversible como unicidad o sorpresa. Estas experiencias son más proclives a las jóvenes generaciones (Koselleck, 2001, pp. 36-37). Recurrencia o reiteración: el segundo conjunto de experiencias se da por oposición al anterior, en tanto se representan en eventos predecibles, reiterados y en duraciones de mediano plazo. Hay una suerte de equilibrio entre la quietud y la sorpresa: "Todo lo que puede decirse acerca de la experiencia de la repetición y el procesamiento de la 
Luego de abordar la relación entre el método histórico y la experiencia, concluye que, aunque guardan relación, no es cierto que los cambios metodológicos afecten la experiencia de manera directa ni tampoco que los cambios de experiencia sean la causa empírica de las transformaciones metódicas. En otras palabras, los acontecimientos históricos se producen sin consultar los métodos; sin embargo, los métodos de la historia deben dar cuenta de las transformaciones o cambios. Una vez resuelto el dilema indaga por las estrategias para captar los acontecimientos a los cuales el historiador se debe enfrentar. Propone tres opciones: registrar, continuar y reescribir la historia.

Los conceptos, entendidos como enunciados, índices o señales y como factores palpables de transformaciones históricas en la formación de la conciencia y el "control de los comportamientos" sociales, se caracterizan por cuatro aspectos:

1) Temporalización, según las categorías sociopolíticas emergentes; 2) democratización del concepto, que se escapa del discurso de los expertos para el uso social; 3) ideologización, esto es, juego de los discursos en el singular colectivo que los aplica en los juegos de poder; y 4) politización. Según Koselleck, los estratos temporales de los conceptos suelen tener tres niveles: duración, cambio y novedad. El primero se ubica en las constantes históricas que logran trascender. El segundo altera su esencia y captura más de un significado. El tercero se refiere a los conceptos que comienzan a abrirse camino, y a los que nuestro autor

unicidad se refiere siempre a las generaciones que conviven, cuyo enriquecimiento recíproco es siempre comunicativamente posible" (p. 40). Nuestro interés en esta estratificación será visible y lo situaremos en un mismo espacio y tiempo. Trascendencia: el tercer conjunto de experiencias ocasionan transformaciones poco visibles aunque más profundas, prolongadas e intensas, y que son objeto del trabajo del historiador. "Estas concepciones humanas del mundo se repiten en ritmos más lentos que el cambio que es directamente experimentable en el transcurso de unas generaciones" (p. 41). denomina neologismos. Las tres generaciones (abuelo, padre e hijo). Por su parte, el trabajo investigativo de Quentin Skinner, miembro de la escuela de Cambridge, es una versión actualizada de la historia de las ideas, en la medida en que busca la recuperación del contexto intelectual de los actores, se apoya en la texto-lingüística y centra su atención en los actos de habla, ${ }^{11}$ en medio de las tensiones o resistencias en las que están situados los actores. Skinner considera que los textos son como actos del habla de los que se puede indagar su fuerza ilocucionaria para develar las intenciones de los protagonistas de los conceptos canónicos. En su primera fase, el autor está más cerca de la escuela francesa que de la alemana, pero luego hará uso de ambas. Skinner (2007) nos permitió pensar en los textos canónicos:

La tarea del historiador [... es estudiar e interpretar un canon de textos clásicos. El valor de estudiar esta clase de historia reside en el hecho de que los textos clásicos sobre ética, política, religión y otros modos de pensamiento contienen una sabiduría sin tiempo bajo la forma de "ideas universales". Como resultado, podemos esperar aprender y beneficiarnos directamente de la investigación de estos "elementos intemporales", puesto que ellos poseen una pertinencia perenne [...]. En otras palabras, debemos estar preparados para leer cada uno de esos textos clásicos "como si fuesen escritos por un contemporáneo". (p. 110) $)^{12}$

Koselleck (2012) lo expresa de la siguiente manera:

El mito y los cuentos de hadas, el drama, la epopeya y la novela se caracterizan por presuponer y tematizar la relación originaria entre el discurso y la

11 Acto de habla o acto elocutivo: clase específica de la acción que se realiza cuando se produce una emisión del habla. Es la unidad mínima de comunicación. El acto de habla se llama ritual (en el análisis del discurso literario) cuando se define en términos de la evaluación de los lectores oyentes (León Gómez, 1984, p. 271).

12 Una parte de mi trabajo se sustentó en este texto que contiene diez ensayos. 
acción, entre el padecimiento, el hablar y el callar. Hacer presente la historia acontecida crea el sentido, que se mantiene digno de ser recordado. Estos es precisamente lo que hacen las historias que utilizan discursos. (p. 17).

\section{Perspectiva histórica en Latinoamérica}

En Latinoamérica la documentación sobre historia de los conceptos no es prolífica. Sin embargo, los trabajos de las universidades de Quilmes, Buenos Aires y Flacso de México, especialmente, muestran que este enfoque viene cobrando fuerza. La forma en que ha venido evolucionando esta perspectiva histórica en el naciente siglo pone de manifiesto un modelo de investigación propio de la modernidad, tiempo en el cual se tejen redes locales, nacionales e internacionales para producir conocimiento trasdisciplinar e interdisciplinar, se intercambian resultados y, una vez concluidos los trabajos, entran en circulación de modo veloz. Este campo de investigación convoca a historiadores, lingüistas, politólogos y sociólogos de distintas naciones, algunos bajo el pretexto de armar diccionarios político-sociales y otros con la intención de captar los procesos locales en un contexto universal. Observamos que en América Latina se hace más referencia a la historia de los intelectuales o de las ideas o conceptos políticos.

La obra iniciada por las Escuelas de Cambridge y Bielefeld avanzó hacia España y Portugal, se expandió en Europa con la red internacional History of Political and Social Concepts Group (HPSCG), del Instituto Iberoamericano de Gotemburgo (Suecia), y ahora se disemina por Latinoamérica, impulsado por entidades de los países señalados. La enorme empresa de un diccionario político-conceptual germano (Geschichtliche Grundbegriffe: historisches Lexikon zur politisch-sozialen Sprache in Deutschland), que iniciaran Brunner, Conze y Koselleck, motivó a un grupo ibérico a desarrollar un proyecto de Diccionario político y social del siglo XIX español (Madrid,
2002), a cargo de Javier Fernández Sebastián y Juan Francisco Fuentes. ${ }^{13}$

\section{La historia de los conceptos en el escenario local}

Colombia tiene una participación menor en la historia de los conceptos, aunque vale resaltar los trabajos del profesor Roland Anrup. Anrup ha dirigido proyectos de investigación no solo en Colombia, sino también en países vecinos como Ecuador y Bolivia. ${ }^{14}$ Aunque no es miembro de la red Iberconceptos, y quizás por ello se muestra como un investigador mordaz contra los regímenes latinoamericanos, ha desarrollado investigaciones sobre problemáticas de la historia reciente contra el relato oficial. Anrup, además de profesor de historia de la Universidad de Gotemburgo (Suecia), ha sido director del Instituto Iberoamericano adscrito a la misma institución. De esta entidad es egresado el profesor argentino Vicente Oieni ${ }^{15}$ quien, junto con Elías Palti, es un referente básico. Los aportes conceptuales y de estudios culturales de Anrup abordan temas de gran complejidad sobre conflictos colombianos, como el desplazamiento, la guerra sucia, la eliminación selectiva de personas y otros campos de tensión recientes.

En el rastreo de autores colombianos se identificó la tesis doctoral del profesor Manuel Horacio Vásquez,

13 Vendría luego la edición del libro L’avènement de l’opinion publique. Europe et Amérique XVIIIe-XIXe siècles (París, 2004), de Joëlle Chassin, labor que trae a Latinoamérica la idea. El proyecto compromete a Latinoamérica y pretende abordar los siguientes conceptos políticos claves: América/americanos, ciudadano/vecino, Constitución, federación/federalismo, historia, liberal/liberalismo, nación, opinión pública, pueblo, república/republicanos.

14 Subrayamos que en estos trabajos los países señalados han sido menos sujeto que objeto de los historiadores mencionados.

15 Oieni dirigió por diez años (1986-1996) el tema de historia latinoamericana en el Instituto Iberoamericano de la Universidad de Gotemburgo. 
titulada La route de la feuille de coca, 1492-1992. Entre l'histoire, la memoire et l'oublie, sustentada en Nantes el 21 de diciembre de 2001 y publicada por Oveja Negra en el año 2012. ${ }^{16}$

\section{La invención del concepto competencia}

Cuando un investigador enfrenta la tarea de encontrar los rastros de un concepto o, lo que es lo mismo, cuando debe deconstruir un discurso - en el sentido fuerte derrideano - en estratos temporales de larga o corta duración, tiene en la historia de los conceptos una potente máquina de trabajo. El concepto de competencia configura historias y estas historias, a su vez, configuran realidades que comprometen a la sociedad y al sujeto. Se enuncia a la par de palabras como revolución y héroe, y anuncia cambios o revoluciones semánticas en una comunidad lingüística. Cuando esto ocurre es porque antes hubo alguna crisis política o social. Se corrobora que los cambios del concepto cambian a los sujetos y que los cambios de los sujetos cambian los conceptos. Los cambios de sentido de un concepto cristalizan en distintos estratos de tiempo cargados de significado que provienen de los discursos del poder en el escenario de disputas político-educativas, lo que en clave foucaultiana significa que el poder produce verdades $y$ formas de conocimiento. ${ }^{17}$

16 Vásquez analizó más de sesenta crónicas y otras fuentes impresas. Levantó un mapa y una lista de evidencias que muestran cómo era observada la hoja de coca desde la época precolombina, en un proyecto de largo aliento y de historia en largos periodos. Además, elaboró otros análisis conceptuales como: a) la identificación y confusión entre los conceptos hoja de coca y cocaína (2012, pp. 217228); b) la confusión en torno al concepto de problema, referido a la hoja de coca, entre la Comisión Peruana y la Comisión de las Naciones Unidas en los inicios de la década del cincuenta (pp. 256-274); c) el concepto de monopolio sobre la hoja de coca esgrimido por la escuela en contra de la hoja de coca para abolir el consumo de este producto vegetal en América del Sur (pp. 500-514).

17 Foucault señala: "La humanidad no progresa de combate en combate hacia una reciprocidad universal, en la que
A lo largo de la investigación sobre diversos autoresactores novelescos de origen inglés, suizo o francés, se entró en diálogo con las prácticas pedagógicas motivadas por supuestas revoluciones auspiciadas en los juegos de poder. Estos autores se renovarán y tomarán nuevas imágenes que cabalgan hasta el siglo XXI, y en los que vemos la simiente de la competencia; aunque es borrosa, su significado está latente, bien redimiendo la competitividad de Smith o el heroísmo y la laboriosidad de Robinson.

\section{Robinson, un sujeto competente}

Robinson coloniza su isla y dibuja las prácticas económicas de la sociedad industrial inglesa y del liberalismo en ascenso. El náufrago siembra trigo y cebada, alfabetiza a Viernes, somete al rebelde Calibán, y luego escribe su diario y registra cada lugar para enseñarle al mundo una isla que dejará de ser virgen, puesto que él la ha invadido con su presencia y su escritura. Las prácticas escriturales de Robinson auguran la modernidad de gobierno liberal: con su labor sobre la tierra, su escopeta y su texto de contabilidad o registro mercantil, introduce el mundo del trabajo de modo organizado y metódico. Así, prescribe y proyecta el tiempo de la modernidad.

Entre tanto, Adam Smith perfila su Riqueza de las naciones a un empresario organizado; diseña un deseo o una posibilidad en medio de una economía perfecta. Los dos ingleses han contribuido a la construcción de otros textos en diversos espacios y tiempos que anuncian condiciones de posibilidad de seres competentes y competitivos.

\footnotetext{
las reglas sustituirán, para siempre a la guerra; instala cada una de esas violencias en un sistema de reglas, y va así de dominación en dominación" (2004, pp. 34, 39-40, como se cita en Castro, 2010, p. 24). Nadie escapa a la guerra, el poder atraviesa por igual a gobernantes y gobernados para producir verdades, resalta Castro.
} 
El difuso enunciado de competencia, en su acepción económica de competitividad, emerge como un proceso económico natural de la oferta y la demanda, sin distanciarse de otras leyes naturales universales, como el evolucionismo darwiniano, en episodios de tensiones entre las naciones por la disputa de los mercados que auspician, al decir de Foucault, un nuevo racismo.

Adam Smith consideró que la competencia era "un proceso natural correcto". Luego, otros autores recrearon sus discursos con nuevos objetivos y proyectos que trocaron en formas y prácticas diversas hasta la modernidad. Por su parte, la metáfora del náufrago inglés y sus subalternos, Ariel y Calibán, se recrean en textos literarios diversos y en distintas capas temporales, en el siguiente orden: Emilio o la educación de Rousseau, Simón Rodríguez y sus discursos pedagógicos robinescos, El triunfo de Calibán de Rubén Darío, Ariel de José Enrique Rodó; De Robinson a Odiseo. Pedagogía estructurativa de José Vasconcelos) y Calibán en esta hora de nuestra América de Roberto Fernández Retamar). Robinson aparecerá además en el cine, en la música y en el teatro de la modernidad. Estos autores traman la narrativa que recorre los estratos temporales signados por tres grandes reformas universitarias, en tiempos y lugares donde cristalizan los discursos y las prácticas pedagógicas, en una gama textual variopinta que anima el concepto de competencia. Este dará un giro inesperado luego de la Segunda Guerra Mundial.

\section{Escritores colombianos competentes}

La intelectualidad colombiana adscribió la primera reforma universitaria que nació en Córdoba en 1918 y que anidó en el seno de los grupos de estudio, sindicales y partidistas de los años treinta. Periódicos como El Espectador, El Tiempo y El Siglo muestran que las figuras más visibles de la élite pedagógica de la primera mitad de siglo bogotano están tocadas por el arielismo modernista, que son reconocidas por sus habilidades para escribir de modo ampuloso y por su capacidad oratoria de estilo grecolatino. Sin embargo, con su escritura y oratoria nombran y producen los acontecimientos del periodo. Desde el nacimiento del siglo XX la producción discursiva determina las prácticas de gobierno. A los iletrados se llegará con la oratoria de la plaza pública e imágenes que cautivan a la población y que van constituyendo los conceptos y prácticas discursivas con los cuales se gobernará y educará al país a lo largo de esta centuria. Las artes del buen decir, y el buen hablar y escribir propiciarán la formación no solo de círculos de estudio, sino también de círculos obreros, que se convierten en el dispositivo de gobierno de la primera mitad de siglo. La ciudad letrada cuece sus discusiones en espacios cerrados como los cafés, las oficinas de los periódicos, las salas del parlamento y el senado, o en los despachos públicos, hasta irrumpir en plazas públicas, calles y escuelas. Estos escenarios serán la tribuna de sus discursos y la audiencia, los sindicatos, los gremios estudiantiles y los electores que emplean sus discursos para resolver sus diferencias en los campos y en las calles. La escritura ampulosa y la oratoria grecolatina, pródiga en recursos metafóricos, circulará de modo recurrente: la intensidad discursiva será luego ferocidad oratoria asociada al juego político y a la capacidad de convocatoria y de agresión al contendor. Así lo mostraron, entre otros, Laureano Gómez (señalado como un hombre, un partido, una nación) o Jorge Eliécer Gaitán (el caudillo, el mártir, el hombre pue$b l o$ ). Veamos un testimonio de la hija del caudillo:

\footnotetext{
Yo amo la lucha, amo la batalla [...]. Esas son las bases religiosas o místicas de cualquier cosa mística frente a la política, frente a una causa, un místico [...]. Si yo oigo el himno nacional se me derraman siempre las lágrimas porque eso es mi papá, la bandera nacional es Gaitán, el escudo de Colombia es Gaitán, el mapa de Colombia, es Gaitán. (Gloria Gaitán, como se cita en Alape, 1983, p. 418).
} 
De igual forma, las efemérides educativas y los textos didácticos pondrán en acción los discursos de poder en un teatro de escenas y símbolos patrios que mutarán entre uno y otro periodo, matizados como "revoluciones educativas" y disputas conceptuales que siempre terminan en reyertas o asonadas.

Los textos señalados, al igual que otros menos narrativos o literarios, como las encíclicas papales, los textos didácticos, las proclamas educativas, las reformas educativas, las investigaciones económicas o lingüísticas, brotan entre una gran dispersión discursiva que parece escrita por la misma pluma. Estos textos, al igual que sus autores, protagonizan acontecimientos y tensiones políticas apropiadas por las élites latinoamericanas y difundidas como verdades inapelables. Así, los discursos producen disputas con las cuales se pretende ocupar un territorio o debilitar al contendor: la prensa, la radio, los libros y los textos didácticos son los dispositivos de difusión, ideologización y empoderamiento de bandos o bandas.

Lo anterior significa que los textos utilizados en este trabajo, literarios o no, se entienden como artefactos culturales o como construcciones culturales resultantes de un contexto sociohistórico determinado. Tales textos son abordados no como documentos sagrados que brindan información incuestionable sino como productos que muestran las distintas representaciones en diferentes estratos temporales.

\section{El Proyecto Manhattan y el Instituto Tecnológico de Massachusetts, constructores de conceptos}

La segunda mitad del siglo XX fue pletórica en conflictos bélicos y tensiones políticas por el reparto territorial del capital pedagógico y educativo nacional e internacional. La excavación y el recorrido sobre el Cono Sur nos condujeron a México y Estados Unidos para luego regresar a Colombia.
La Segunda Guerra Mundial produjo dos proyectos de gran impacto: uno, el Proyecto Manhattan (PM), que creó la bomba atómica; y el segundo, el Instituto Tecnológico de Massachusetts (ITM), que creó el moderno concepto de investigación en la educación superior y sobre el cual se instala el discurso de competencia lingüística. El PM no solo creó la bomba atómica, sino que también estrechó los lazos bélicos, educativos y económicos entre Inglaterra y Canadá, y el nuevo imperio de donde emergen los conceptos de eficiencia y empresa investigativa transnacional, sobre los cuales se funda la modernidad educativa y productiva. Entre tanto, del ITM ${ }^{18}$ brotaron los conceptos de modelo, teoría de campo, modelo comunicativo, cibernética, teoría de sistemas y, en medio de ellos, el de competencia lingüística. Pueril sería señalar a Noam Chomsky, protagonista de este concepto, como el promotor de los episodios señalados. Sin embargo, desde entonces el concepto se traslapa de modo diverso, y con alusiones que se escapan de su cepa para tomar lugar y formas variopintas y caprichosas en los juegos de poder discursivo por el control de la investigación, la educación y el trabajo.

El referente que permitió este hallazgo fue el texto del filósofo y profesor José Vasconcelos, titulado De Robinson a Odiseo. Pedagogía estructurativa, publicadoen 1935. Al ir tras las huellas de Robinson se hicieron dos hallazgos fundamentales: 1) el profesor e ingeniero de la Universidad de Cornell, Dexter S. Kimball, publicó en 1929 un texto valioso, Economía industrial -útil a nuestros intereses-, en el que culpa a los empresarios estadounidenses de haber provocado la crisis económica del 29 a causa de su empirismo e incompetencia; 2) uno de los actores del PM, y luego director del ITM, el señor James Bryant Conant, publicó en 1953, luego de pasada la Segun-

18 Cabe resaltar que algunos de los más connotados investigadores del Proyecto Manhattan, además de haber recibido el Premio Nobel, trabajaron como investigadores en el ITM. 
da Guerra, La educación en un mundo dividido. Función de las escuelas públicas en nuestra sociedad, en el que señala la importancia de ver la educación superior como si esta fuera el centro de las operaciones de guerra. Al igual que Kimberly con respecto a la depresión económica, Conant (1948/1953) interroga la educación: ¿ipor qué se debe enseñar arte y la literatura de Shakespeare en lugar de las historias cómicas? Ante lo cual señala: “[...] el humanista debe reexaminar constantemente la naturaleza de sus premisas y buscar nuevos aliados en esta época de la máquina y del hombre común" (p. 101). La hipótesis de Conant es que el público no es homogéneo, por lo tanto la enseñanza no puede serlo: "manejar un camión, por ejemplo, podrá proporcionar una salida a quienes gustan de la velocidad y el sentimiento de poder que proviene de manejar una máquina moderna" (p. 102). Por lo tanto, "enseñar literatura $\mathrm{y}$ arte de la misma manera equivale a suponer que la dieta de un leñador de los bosques del norte debe ser igual a la de un oficinista de una ciudad del sur" (p. 105) ¿Competencias laborales vs. competencias de lectura y escritura?

La depresión económica se dio a la par con el proyecto conocido como la Revolución en Marcha, impulsado por el presidente Alfonso López Pumarejo, mediante el cual se dinamizó la incipiente industria y se quiso hacer la primera reforma a la educación superior (especialmente de la Universidad Nacional). Por otra parte, tuvo lugar la inclusión de algunos de los enunciados de la Reforma de Córdoba (1918) y la Segunda Guerra Mundial coincidió también con la creación de ACPO-Sutatenza, antecedente del SENA y simiente de la tecnología instruccional y los modelos de formación para el trabajo.

La grandes empresas científicas, el PM y el ITM modificaron las prácticas empresariales, investigativas y educativas. Los hallazgos de las investigaciones sobre las máquinas de guerra recurrieron a la psicología, la lingüística, la biología, las ciencias de la comunicación, la cibernética y otras disciplinas emergentes. Estas fueron captadas en primera instancia por los procesos productivos, los medios de comunicación y luego por organismos internacionales, como la OIT, la Unesco, el Centro Europeo para el Desarrollo de la Formación Profesional (Cedefop) o el Centro Interamericano para el Desarrollo del Conocimiento en la Formación Profesional (Cinterforen), para la construcción de modelos investigativos y pedagógicos. Estos organismos ponderan la investigación sobre el conocimiento humano y se abrigan en el trabajo de investigadores reconocidos en la esfera internacional para trazar las políticas globales de educación: las modernas encíclicas científicas y formativas saldrán de estas nuevas Romas.

Desde mediados del siglo XX cuatro discursos agitaron los campos y las prácticas pedagógicas en Colombia y en países vecinos: las pedagogías instruccionales, las populares, las críticas y las constructivistas. Cada una tomó sus propias formas y tuvo sus defensores. En las décadas de los cincuenta y los sesenta fueron notorias las pedagogías instruccionales (impulsadas desde Estados Unidos y España en entidades colombianas como Acción Cultural Popular [ACPO], el SENA y el Ministerio de Educación Nacional [MEN]). Las décadas de los setenta y los ochenta fueron fecundas en pedagogías críticas y populares, y finalizando el siglo, hasta avanzar al XXI, emergieron las pedagogías constructivistas o cognitivistas por las cuales se profesa hoy una devoción inquebrantable. Sobre diversos sedimentos discursivos dejados por cada una de estas pedagogías se instaló el discurso de las competencias.

Las pedagogías instruccionales y las populares, provenientes de Estados Unidos y España, se ocuparon de calmar los ánimos belicistas, de disciplinar y responder a la producción. Ante este panorama, filósofos y pedagogos reaccionaron con reflexiones anti- 
canónicas, en la búsqueda de conceptos libertarios y de darle un rostro al ser latinoamericano.

Si bien la guerra dispuso un esquema educativo de corte empresarial e instruccional, luego se produjo una corriente crítica en lo filosófico, social, político y pedagógico, tanto en Europa como en América Latina. Posteriormente, en la segunda mitad del siglo XX, emergió una corriente de pedagogos constructivistas que ya no solo abordaban los universales del pensamiento, sino que también se interesaron por el pensamiento, el conocimiento y el aprendizaje del maestro y su discípulo en eventos didácticos específicos; es decir, se situó el radio de acción de las investigaciones en un sujeto concreto.

Organismos internacionales y autores de discursos científicos - como el Instituto Tecnológico de Massachusetts, caso Chomsky; o la Unesco, caso Piaget- comenzaron sus disputas desde los laboratorios. Así hicieron visible la palabra competencia hasta convertirla en una utopía anhelada y en un concepto metahistórico, imprescindible para la educación y el trabajo. Valga recordar las disputas discursivas de Chomsky con Piaget o con Foucault, en las que el concepto de competencia cobró fuerza. ${ }^{19}$

Entre las distintas formas y configuraciones propias del significado de competencia, se fortalece la acepción de disputa que se fundió con la de competitividad, más que con la de competencia lingüística. La posibilidad de intercambiar en ocasiones ambos conceptos apunta a desplazamientos estructurales en el conjunto del tejido social, que solo provocan diferentes respuestas políticas. La antítesis y síntesis entre competencia y competitividad fue aupada por

19 El debate entre Foucault y Chomsky fue transmitido por la cadena de televisión de la Universidad de Ámsterdam, el 8 de octubre de 1971, y hoy se puede ver en Youtube. El debate entre Chomsky y Piaget se dio del 10 al 13 de octubre de 1975 en la Abadía de Rayaumont y tuvo enorme difusión. conceptos extraños a ella, como revolución, aprendizaje, evaluación, fábrica del conocimiento, estandarización o aprendizaje, habiéndose producido un proceso de resemantización que ha convertido una palabra en un concepto propio de un campo, o bando, mediante el cual se definen identidades y nexos grupales. Bien sea para defender o para atacar, su uso crece de modo exponencial en medio o gracias a las disputas entre diversos bandos.

Nuestra panorámica registró algunos acontecimientos educativos e investigativos de la Segunda Guerra Mundial que hicieron posible que el concepto ganara en riqueza y se dispersara de modo impredecible por Norteamérica, Europa y Latinoamérica y, de modo particular, por Colombia. En este país, a fines del siglo XX los textos que usaban esta palabra eran apenas unos pocos especializados en economía o lingüística. Hoy, en contraste, el término se repite en miles de textos. Basta con aplicar el buscador de Google y se comprobará que pasa del millón de definiciones.

Latinoamérica recogió los despojos de guerras ajenas para construir sus planes económicos y educativos, mediante los cuales empoderó el discurso de las competencias que redimió el heroísmo de Robinson, un protagonista de la revolución inglesa incrustado en los estratos de la historia. Algunos grupos pedagógicos colombianos alimentaron los discursos canónicos y acogieron múltiples enunciados de competencias para producir una enorme proliferación y dispersión discursiva que inundó el universo educativo y laboral.

Un sujeto heroico, competente, competitivo, se abrió paso e instaló una verdad que transformó a la sociedad laboral y educativa. Ya no solo se atrapa a los niños en la escuela; ahora se compromete al joven universitario o al trabajador experimentado, que están expuestos y dispuestos a una formación continua, y a los que se les dice siempre que su formación 
aún no concluye. Se trata entonces de competir, de tener la posibilidad de alcanzar la cima, de disputar el mejor lugar en medio de una ansiedad colectiva de la que nadie quiere estar por fuera. Todas las acuñaciones del concepto de competencia tienden a un cambio global que motiva, además, una aceleración permanente.

Ser competente, ser competitivo, es el anhelo. Lo contrario es el descrédito: el nefasto calificativo de incompetente, empleado por primera vez por el norteamericano Dexter Kimball y por José Ingenieros, es la amenaza. El concepto se concentra en un singular colectivo desde 1930 y adquiere un tono trascendental para convertirse en un principio regulador del conocimiento y la acción humana. La aceleración pertenece hoy a la experiencia cotidiana acumulada por el crecimiento, la expansión global y el poder de la sociedad mediática invadida por redes virtuales.

\section{Literatura didáctica}

La escritura de Simón Rodríguez entra en diálogo con El triunfo de Calibán de Rubén Darío, el Ariel de José Enrique Rodó, De Odiseo a Robinson de José Vasconcelos. Los cuatro son el punto de contacto entre Europa y América y permiten la entrada del discípulo Robinson a las incipientes universidades y empresas del siglo XX. Estos autores-actores crean su propio sujeto heroico y letrado, y la acepción criolla de un racismo puesto como marca distintiva de la pobreza y la riqueza. Sus discursos estimulan una versión moderna de trabajador obediente en circunstancias que agitan enunciados como revolución, civilización, raza y barbarie. La dispersión de archivo nos condujo a documentos relacionados con la depresión económica del 29, evento que se mostró como el punto de quiebre entre las sociedades capitalistas de Europa y Estados Unidos y el lugar de emergencia del concepto de competencia laboral.
En este 1947 se anuncia en Colombia la apertura de ACPO-Sutatenza que habría de constituirse en el proyecto mediático educativo popular más grande de Latinoamérica del siglo pasado. Diez años más tarde, en 1957, se inauguró el Servicio Nacional de Aprendizaje SENA, bajo el lema de la revolución de la esperanza, y se convirtió en el mayor centro de formación obrera del país. Estos dos eventos trazan un importante estrato temporal y son una fuente discursiva para estudiar el concepto de competencia en Colombia, que hoy propone un cambio en la industria y una segunda reforma en la educación superior.

Desde finales del siglo XX los arcos temporales se van haciendo más cortos en la medida en que la tecnología apresura los procesos y se avanzó hacia el siglo XXI. Este ordenamiento se adelanta sobre la base conceptual que propone que en la actualidad se experimenta una aceleración del tiempo. La historia del concepto de competencia está atada a un interés de la modernidad por modelar o atrapar al sujeto y legitima su pretensión en los hallazgos de disciplinas como la economía, la lingüística, la psicología, la cibernética y la ingeniería de la comunicación.

Si bien se encontraron enunciados de competencia entre los documentos consultados, esta palabra puede considerarse como un concepto hasta finales del siglo XX y comienzos del XXI. Es entonces cuando el concepto de competencia se devela, toma fuerza y se instala en Colombia, en universidades, empresas, instituciones públicas, bases de datos, libros, revistas, instituciones educativas, entre otras, al tiempo que se anuncia, otra vez, una revolución educativa durante las administraciones de los presidentes Andrés Pastrana Arango (1998-2002) y Álvaro Uribe Vélez (2002-2006 y 2006 2010), cuando se propone una tercera reforma de la educación superior en Colombia. Estos proyectos avanzan pero regresan, transforman pero reinstalan viejas metáforas. De 
nuevo, hay un Robinson, más mediático y eficiente; más veloz y ocupado en su trepidante búsqueda.

Además de lo señalado, el concepto de competencia genera confrontaciones, es un proyecto de la globalización; y, lo más importante para nosotros, propicia un atractivo campo de investigación.

\section{Resultados}

Hoy la palabra competencia es un concepto gracias a que, en tanto sumatoria anárquica de enunciados, índices o señales, genera transformaciones históricas en la formación de la conciencia y en el "control de los comportamientos" sociales bajo la perspectiva de Koselleck. En primer lugar, por la temporalización, pues aparece en distintas capas temporales y en lugares impredecibles. En segundo lugar, logró un proceso de democratización y escapó del discurso de los expertos para ganar uso social. En tercer lugar, por la ideologización, pues logró meterse en el escenario de los discursos en el singular colectivo y que fuera aplicado en los juegos de poder. Y, por último, en lo que respecta a la politización de los sujetos que entran en tensiones para defender sus campos de poder.

La palabra ganó representatividad histórica en singular y en plural, pues desde su surgimiento ha sido resignificada de modo reiterado por disciplinas tales como la psicología, la lingüística, la pedagogía, la historia, la literatura, la sociología, el derecho, las ciencias de la comunicación y las ciencias del trabajo. De ello dan testimonio la densidad documental y el archivo abordados en esta investigación.

Se encontró que cuanta más tensión haya entre los usuarios, es mayor la producción discursiva y el empleo del concepto, así como la posibilidad de que este se incorpore en la construcción de sujetos. En el proceso histórico sufrido por la palabra competencia hay desplazamientos, permutaciones, inclusiones, canales y usos con los que se forja la educación y son llevados a sus prácticas pedagógicas y discursivas que construyen un sujeto educativo.

Competencia, más que una palabra, es un concepto por tres razones. La primera es que está cargado de connotaciones y significaciones inscritas en diversos sistemas semánticos, que producen hechos y prácticas pedagógicas en el escenario nacional. La segunda, porque, en tanto texto, no está concluido por completo ni fijado definitivamente, así esté escrito y avalado por los diccionarios o por los expertos; posee una estructura temporal interna que está mediada por condiciones de tiempo y espacio. Y la tercera, que es consecuencia de las dos anteriores, la transformación estructural que sufre el concepto de competencia afecta algunas prácticas pedagógicas y productivas, amén de embargar proyectos locales, nacionales e internacionales; así mismo afecta la construcción del sujeto. De este modo se genera un atractivo campo de tensiones político-sociales que emergen de la educación.

\section{Conclusiones}

El uso recurrente del enunciado competencia como un arma del lenguaje lo enriqueció hasta convertirlo en concepto. Cuando los actores del escenario educativo pretenden visibilidad y reconocimiento en el juego político, sin importar el bando o lugar que ocupen en el campo de las confrontaciones, comprometen sus discursos con el concepto, potenciándolo y resemantizándolo. Una vez hecho concepto, se instaló en campos educativos y productivos hasta hacerse indispensable en los escenarios donde se toman decisiones sobre la educación. Una vez hecho concepto se instaló en campos educativos y productivos y se hizo indispensable en los escenarios donde se toman decisiones sobre la educación. Si hoy se indagan las bases de datos relacionadas con educación y trabajo de instituciones públicas y privadas, periódicos, folletos, libros y revistas, impresos o virtuales, se observará el posicionamiento del concep- 
to. Su crecimiento se ha dado de modo exponencial y cada día gana más densidad semántica, resignifica los proyectos educativos y al sujeto en lo moral, lo ético y lo político. Señalamos dos hallazgos claves. El primero es que los enunciados relacionados con las competencias producen prácticas y discursos pedagógicos, y solapan crisis que suelen emerger precedidas del concepto revolución: un día fueron revoluciones con fines de alfabetización o para el saneamiento de la población; otro, para la formación de trabajadores; o, más recientemente, son revoluciones educativas que auspician competencias y renovaciones que insinúan un eterno retorno del náufrago y competente Robinson Crusoe, que resuelve una nueva crisis. El segundo es que la Segunda Guerra Mundial fue el nicho que auspició los conceptos de empresa investigativa, educación superior e internacionalización, que son el caldo de cultivo del concepto moderno de competencia.

Desde el periodo republicano, la disputa por el control de la educación superior y el trabajo produjo diversas tensiones que se ven reflejadas en la producción de textos canónicos literarios e institucionales, que se editan con nuevos discursos. La palabra se hizo concepto, se instaló de modo azaroso en innumerables bibliotecas y redes virtuales, entró a la intimidad de los usuarios y hoy cabalga sobre los discursos pedagógicos y económicos, genera tensiones e infunde respeto en un proceso de aceleración permanente.

Algunas tensiones discursivas que se produjeron en los campos de poder de la intelectualidad local tienen cierto matiz pedagógico, que proviene de la república y repta hasta la primera mitad del siglo XXI, en una suerte de eterno retorno con tres propósitos comunes: la alfabetización de la población con el fin de inculcar discursos institucionales, las disputas por el control del campo educativo y el empleo de discursos foráneos para defender o denunciar al contendor. En cada etapa está latente el concepto de revolución. Si se acepta este planteamiento, es posi- ble trabajar sobre los textos y autores representativos de los discursos en juego. Por tal razón, se abordó la metáfora de Robinson Crusoe, que aparece en uno y otro periodo, y la obra de autores-actores que defienden posturas discursivas que producen prácticas pedagógicas.

En medio de disputas conceptuales entre académicos, grupos de investigación e instituciones, el concepto logró convertirse en la última década en una utopía que anhelan alcanzar educadores y empresarios, y devino en una categoría metahistórica que sirve para gobernar los procesos laborales y educativos.

El lenguaje empleado en textos canónicos y en documentos institucionales es un observatorio de los juegos de poder, habitado por los distintos regímenes o normas de participación grupal que permiten deshabilitar, incluir o excluir, censurar o aprobar palabras que aspiran a convertirse en conceptos, según los contextos y tensiones espacio-temporales en los cuales nos debatimos los usuarios de la lengua.

\section{Reconocimientos}

Este artículo es el resultado de la tesis doctoral Las ofensivas conceptuales sobre competencias en el campo de la educación superior y el trabajo en Colombia. Periodo 1957-2004" (Convenio Interinstitucional Universidad Pedagógica Nacional, Universidad Distrital y Universidad del Valle, 2012).

\section{Referencias}

Alape, A. (1983). El Bogotazo. La Habana: Casa de las Américas.

Anrup, R. (2009). Una tragedia a la colombiana. Bogotá: Editorial Buena semilla.

Anrup, R. (2011). Antígona y Creonte. Rebeldía y Estado en Colombia. Bogotá: Crónica. 
Arendt, H. (2005). La condición humana (vol. 15). México: Planeta.

Austin, J. L. (1991). Cómo hacer cosas con palabras (1. a ed., G. Carrió, trad.). Barcelona: Paidós.

Conant, J. B. (1948/1953). La educación en un mundo dividido. Función de las escuelas públicas en nuestra sociedad (3. ${ }^{\text {a }}$ ed., A. R. Piérola, trad.). Buenos Aires: Nova.

De Saussure, F. (2005). Curso de lingüistica general (C. Bally, A. Sechehaye y A. Riedlinger, Eds.). Buenos Aires: Losada.

Derrida, J. (1971). De la gramatología. Buenos Aires: Siglo XXI.

Dilthey, W. (1960). La historia de la pedagogía (5.a ed.). Buenos Aires: Losada.

Fernández Sebastián, J. (2010). Diccionario de conceptos políticos clave en el Río de la Plata (primera mitad del siglo XIX). Recuperado el 15 de junio de 20120, de foroiberoideas.cervantesvirtual.com/news/data/30.pdf:

Foucault, M. (1979). La arqueología del saber $\left(66^{\mathrm{a}}\right.$ ed.). México: Siglo XXI.

Foucault, M. (2005). El orden del discurso (A. González, trad.). Barcelona: Tusquets.

Gadamer, H. G. (2002). Acotaciones hermenéuticas (R. Agapito, trad.). Madrid: Trotta.

Heidegger, M. (2005). Ser y tiempo (J. E. Rivera Cruchaga, trad.). Santiago de Chile: Universitaria.

Kimball, D. (1929/1942). Economía industrial. (M. Gleason Álvarez, trad.). México: Fondo de Cultura Económica.
Koselleck, R. (1993). Futuro pasado: para una semántica de los tiempos históricos (N. Smilg, trad.). Barcelona: Paidos.

Koselleck, R. (2001). Los estratos del tiempo: estudios sobre historia (E. J. Palti, introducción; D. Inneraty, trad.). Barcelona: Paidós.

Koselleck, R. (2004). Historia / historia (A. Gómez Ramos, trad.). Madrid: Trotta.

Koselleck, R. (2007). Crítica y crisis. Estudio sobre la patogénesis del mundo burgués. (R. de la Vega y J. Pérez de Tudela, trads.). Madrid: Trotta.

Kosselleck, R. (2012). Historias de conceptos. Estudios sobre semántica y pragmática del lenguaje político y social (L. Fernández Torres, trad.). Madrid: Trotta.

Koselleck, K. y Gadamer, H. (1997). Historia y hermenéutica (J. L. Villacañas y F. Oncina, introducción; F. Oncina, trad.). Barcelona: Paidós.

Kuhn, T. (2006). Estructura de las revoluciones científicas (13. ${ }^{\mathrm{a}}$ ed.). México: Fondo de Cultura Económica.

León Gómez, J. B. (1984). Tres momentos estelares en lingüística. Bogotá: Instituto Caro y Cuervo.

Maldonado, M. Á. (2012). Las ofensivas conceptuales sobre competencias en el campo de la educación superior y el trabajo en Colombia. Periodo 19572004. Tesis doctoral no publicada, Universidad Pedagógica Nacional, Bogotá, Colombia.

Oieni, V. (2005). Notas para una historia conceptual de los discursos políticos. Anales 7-8, 27-62.

Orestes, H. (Comp.). (2001). Carl Schmitt, teólogo de la política. México: Fondo de Cultura Económica. 
Palti, J. E. (2001). Aporías. Tiempo, modernidad, historia, sujeto, nación, ley. Buenos Aires: Alianza.

Palti, J. E. (2003). La nación como problema. Los historiadores y la "cuestión nacional". Buenos Aires: Fondo de Cultura Económica.

Palti, J. E. (2007). La invención de una legitimidad. Razón y retórica en el pensamiento mexicano del siglo XIX (un estudio sobre las formas del discurso político). México: Fondo de Cultura Económica.

Rodríguez, S. (1794/2001). Estado actual de la escuela y nuevo establecimiento de ella. En Obras completas de Simón Rodríguez (t. 1, reedición facsimilar). Caracas: Presidencia de la República.

Rodríguez, S. (1975). Obras escogidas de Simón Rodríguez. Caracas: Bloque de Armas.

Rojas Osorio, C. (2006). Genealogía del giro lingüistico. Medellín: Universidad de Antioquia.

Rorty, R. (1967/1990). El giro lingüístico (G. Bello, trad.). Barcelona: Paidós.
Searle, J. (2001). Actos del habla. Ensayo de filosofía del lenguaje (5. ${ }^{\mathrm{a}}$ ed.; L. M. Valdes Villanueva, trad.). Madrid: Cátedra.

Skinner, Q. (2007). Lenguaje, política e historia (C. Fagman, trad.; E. Rinesi, prólogo). Buenos Aires: Universidad Nacional de Quilmes.

Suárez M., J. O. (2005). Richard Rorty: el neopragmatismo norteamericano. Medellín: Instituto de Filosofía de la Universidad de Antioquia.

Trujillo Paredes, L. F. (2009). Análisis crítico del concepto de sociedad civil en los pronunciamientos oficiales del Gobierno colombiano. Periodo 1994-2006. Tesis de pregrado no publicada, Universidad del Rosario de Bogotá.

Vásquez, M. H. (2012). La ruta de la hoja de coca, 1492-1992: entre la historia, la memoria y el olvido. Bogotá: Oveja Negra.

Wittgenstein, L. (2003). Tractatus logico-philosophicus. Madrid: Alianza. 